Check for updates

Cite this: RSC Adv., 2018, 8, 21505

\title{
Core/shell upconversion nanoparticles with intense fluorescence for detecting doxorubicin in vivo
}

\author{
Junshan $\mathrm{Hu}, \uparrow^{\mathrm{a}}$ Shiping Zhan, $\uparrow^{\mathrm{a}}$ Xiaofeng $\mathrm{Wu}{ }^{\text {tb }}$ Shigang $\mathrm{Hu}^{\mathrm{b}}$ Shaobing $\mathrm{Wu}^{\mathrm{a}}$ \\ and Yunxin Liu (iD)*a
}

Doxorubicin (Dox) is a chemotherapy medication used to treat cancer. Herein, we report a rapid and efficient method for detecting Dox in vivo based on a $\mathrm{NaGdF}_{4}: \mathrm{Yb}^{3+}, \mathrm{Er}^{3+} \mathrm{aNaYF}_{4}$ core/shell upconversion nanoparticles (UCNPs) probe. We found that the intensity ratio of green to red emission (IGVRE) bands of the core/shell $\mathrm{NaGdF}_{4}: \mathrm{Yb}^{3+}, \mathrm{Er}^{3+} \mathrm{aNaYF}_{4}$ nanoparticles was sensitive to Dox in blood samples, and drops as the concentration of Dox increases. In addition, the proposed UCNPs probe possessed the advantage that no nanoparticles leaked into the living body, thus overcoming the intrinsic defect (difficulty in removing UCNPs from blood vessels) of the fluorescence resonance energy transfer (FRET) approach. This proposed UCNP probe design and results may provide some guidance for the real-time and efficient detection of Dox, and can be helpful in biomedical applications.

Received 5th April 2018

Accepted 17th May 2018

DOI: $10.1039 / \mathrm{c} 8 \mathrm{ra02928h}$

rsc.li/rsc-advances

In this study, the $\mathrm{NaGdF}_{4}: \mathrm{Yb}^{3+}, \mathrm{Er}^{3+} @ \mathrm{NaYF}_{4}$ core/shell

\section{Introduction}

Cancer treatment is a worldwide challenge. Doxorubicin, as one of the most efficient anti-cancer drugs, has been commonly used for cancer therapy. ${ }^{1,5}$ Apart from the function of killing cancer cells, the residual Dox in the human body will also cause some unexpected damage, ${ }^{1-4}$ such as cardiotoxicity, liver toxicity, and myelotoxicity. Thus, the rapid and precise detection of Dox in vivo becomes a significant challenge during cancer treatment. At present, the high performance liquid chromatography (HPLC) method ${ }^{13-18}$ is used to detect the concentration of the anticancer agent. For example, Wang et al. reported a UCNP based fluorescent biolabel for the detection of carcinoembryonic antigen. ${ }^{15}$ However, the HPLC method also encounters some shortcomings in the sample pretreatment, such as complex process, ${ }^{19-24}$ long detection cycle $^{8,25}$ and low sensitivity. ${ }^{26-32}$ In addition, assessing the toxicity of cancer drugs to biological tissues is very important ${ }^{5,33-38}$ and valuable to ensure the health of humans and other creatures. ${ }^{6-8,39,40}$ In the commonly used biodetection approach, the UCNPs usually need to be injected into the living body, but it is hard to remove from blood vessels, which can be considered as the intrinsic defect of the fluorescence resonance energy transfer based biodetection approach. Herein, we propose a feasible method for the detection of Dox in vivo based on inorganic core-shells on capillary glass tubes, which improved the detection rate and accuracy for Dox sample analysis as well as real-time analysis.

\section{${ }^{a}$ Department of Physics and Electronic Science, China}

${ }^{b}$ Department of Information Science, Hunan University of Science and Technology, Xiangtan 411201, China. E-mail: lyunxin@163.com

$\dagger$ contributed equally to this study. upconversion nanoparticles, which can convert lower energy infrared photons to higher energy visible-light photons, were adsorbed onto the inner wall of a capillary glass tube to form a Dox detection probe. This probe was linked with the optical fibers for introducing the $980 \mathrm{~nm}$ infrared excitation light and providing the emission light. ${ }^{1-4,6}$ The proposed probe can not only accurately detect the concentration of doxorubicin in vivo, but also avoids the leakage of the nanoparticles to the blood, which is different from the previous detection method based on fluorescence resonance energy transfer (FRET). ${ }^{5,7-12,28,35}$

\section{Experimental section}

\section{Reagents and chemicals}

The reagents oleic acid (OA) (90\%), octadecene (ODE) (90\%), $\mathrm{NaOH}(98 \%), \mathrm{NH}_{4} \mathrm{~F}$ (98\%), methanol (99\%), polyethylene glycol (PEG) (90\%), doxorubicin (Dox), $\mathrm{LnCl}_{3} \cdot 6 \mathrm{H}_{2} \mathrm{O}(\mathrm{Ln}=\mathrm{Gd} / \mathrm{Y}, \mathrm{Yb}$ and $\mathrm{Er})(99.99 \%), \mathrm{C}_{2} \mathrm{H}_{5} \mathrm{OH}(90 \%)$, cyclohexane (90\%), capillary glass tube (CGT) (outside diameter $=120 \mu \mathrm{m}$ ), Y-type optical fiber, and polymethylmethacrylate (PMMA), were purchased from Sigma-Aldrich. Deionized water was used to prepare solutions. All other reagents were of AR grade and used directly without further purification.

\section{Synthesis}

Upconversion nanoparticles were synthesized by a general solvothermal method. ${ }^{3}$ Briefly, $0.8 \mathrm{~mL}$ of $\mathrm{LnCl}_{3}(0.4 \mathrm{mmol}$, $\mathrm{Ln}=$ $\mathrm{Gd} / \mathrm{Y}, \mathrm{Yb}$, and $\mathrm{Er}$ ) aqueous solution was mixed with $15 \mathrm{~mL}$ of $\mathrm{OA}$ and $15 \mathrm{~mL}$ of ODE in a three-neck round-bottom flask. The resulting mixture was heated at $140{ }^{\circ} \mathrm{C}$ under argon flow for $30 \mathrm{~min}$ to form a clear light yellow solution. After cooling to 
$60{ }^{\circ} \mathrm{C}, 5 \mathrm{~mL}$ methanol solution containing $0.074 \mathrm{~g}$ of $\mathrm{NH}_{4} \mathrm{~F}$ and $0.05 \mathrm{~g}$ of $\mathrm{NaOH}$ was added and the solution was vigorously stirred for $30 \mathrm{~min}$. Then, the slurry was slowly heated and kept at $110{ }^{\circ} \mathrm{C}$ for $10 \mathrm{~min}$ to remove methanol. Next, the reaction mixture was protected with argon atmosphere, quickly heated to $325{ }^{\circ} \mathrm{C}$, and maintained at this temperature for one hour. Finally, the reaction was cooled to room temperature naturally, and the nanoparticles were collected with ethanol by centrifugation at $8000 \mathrm{rpm}$ for $5 \mathrm{~min}$. The obtained precipitate was washed with ethanol three times by centrifugation. The UCNPs prepared by this method have excellent dispersibility, regular morphology, controlled size, and good reproducibility., ${ }^{\mathbf{3 , 5}, 41}$

Surface modification of OA-UCNPs with PEG. The surface modification with PEG was conducted according to previous protocols with slight modification. In brief, $500 \mu \mathrm{L}$ stock cyclohexane solution of $\mathrm{NaGdF}_{4}: \mathrm{Yb}^{3+}, \mathrm{Er}^{3+} @ \mathrm{NaYF}_{4}$ core/shell nanoparticles in oleic acid was added to ethanol and acetic acid aqueous solution ( $3 \mathrm{v} / \mathrm{v} \%$ ) and left undisturbed for $30 \mathrm{~min}$. Subsequently, the nanoparticles were precipitated by centrifugation at $3500 \mathrm{rpm}$, and the supernatant was discarded. The collected nanoparticles were dispersed in aqueous solution with a drop $(\sim 0.3 \mathrm{~mL})$ of PEG. ${ }^{5}$ Then, the precipitate was separated by centrifugation after vigorous stirring for 1 hour at $26{ }^{\circ} \mathrm{C}$, rinsed with ethanol three times to remove the unreacted PEG, and readily dissolved in water. The prepared solution was filtered through a $0.22 \mu \mathrm{m}$ syringe filter to remove larger aggregates. PEG-UCNPs were thus formed.

Model of UCNPs@CGT. The proposed probe exhibits triple layered configuration. The optical fiber comprises the core, which is covered by the core-shell UCNPs and the capillary glass tube, in sequence. The UCNPs were absorbed in the inner surface of the capillary glass tube by the capillary action. First, the capillary glass tube was immersed in the UCNPs solution for a few seconds to adsorb some amount of UCNPs solution by capillary action. Then, the solvent was evaporated, due to which the nanoparticles attached to the inner surface of the capillary glass tube. This procedure was repeated several times to form a close layer of the UCNPs. This operation was repeated three times. PMMA blocked one end of the capillary glass tube. Finally, as shown in the inset of Fig. 4, the UCNPs are dispersed homogeneously in CGT and can emit visible-light radiation under the excitation of a $980 \mathrm{~nm}$ laser diode.

Detection of Dox by the UCNPs@CGT probe. Dox in blood was detected by the proposed UCNPs@CGT probe. For this procedure, we used a y-type optical fiber. The two pronged ports of the y-type optical fiber connected with the $980 \mathrm{~nm}$ laser diode and the fluorescence spectrum detection instrument, while the other single port connected with the UCNPs probe. We injected this probe into the blood vessel of the living mice, and detected the concentration of Dox based on the band overlap between the absorption of Dox and the emission of $\mathrm{NaGdF}_{4}$ :$\mathrm{Yb}^{3+}, \mathrm{Er}^{3+} @ \mathrm{NaYF}_{4}$ by the ratio of green to red emission band intensity in fluorescence spectra.

\section{Characterization}

The crystal morphology and size of the as-prepared nanocrystals were examined with an $\mathrm{H}-7650 \mathrm{C}$ transmission electron microscope (TEM), with a tungsten filament at an accelerating voltage of $80 \mathrm{kV}$. High resolution transmission electron microscopy (HRTEM) images were obtained on a JEM-3010 transmission electron microscope operated at $200 \mathrm{kV}$. The EDS spectra were measured by an Oxford Energy Dispersive Spectrometer. The upconversion luminescence emission spectra were recorded on a Hitachi F-2700 fluorescence spectrophotometer, coupled with a NIR $980 \mathrm{~nm}$ laser as the power source. All measurements were carefully carried out at room temperature.
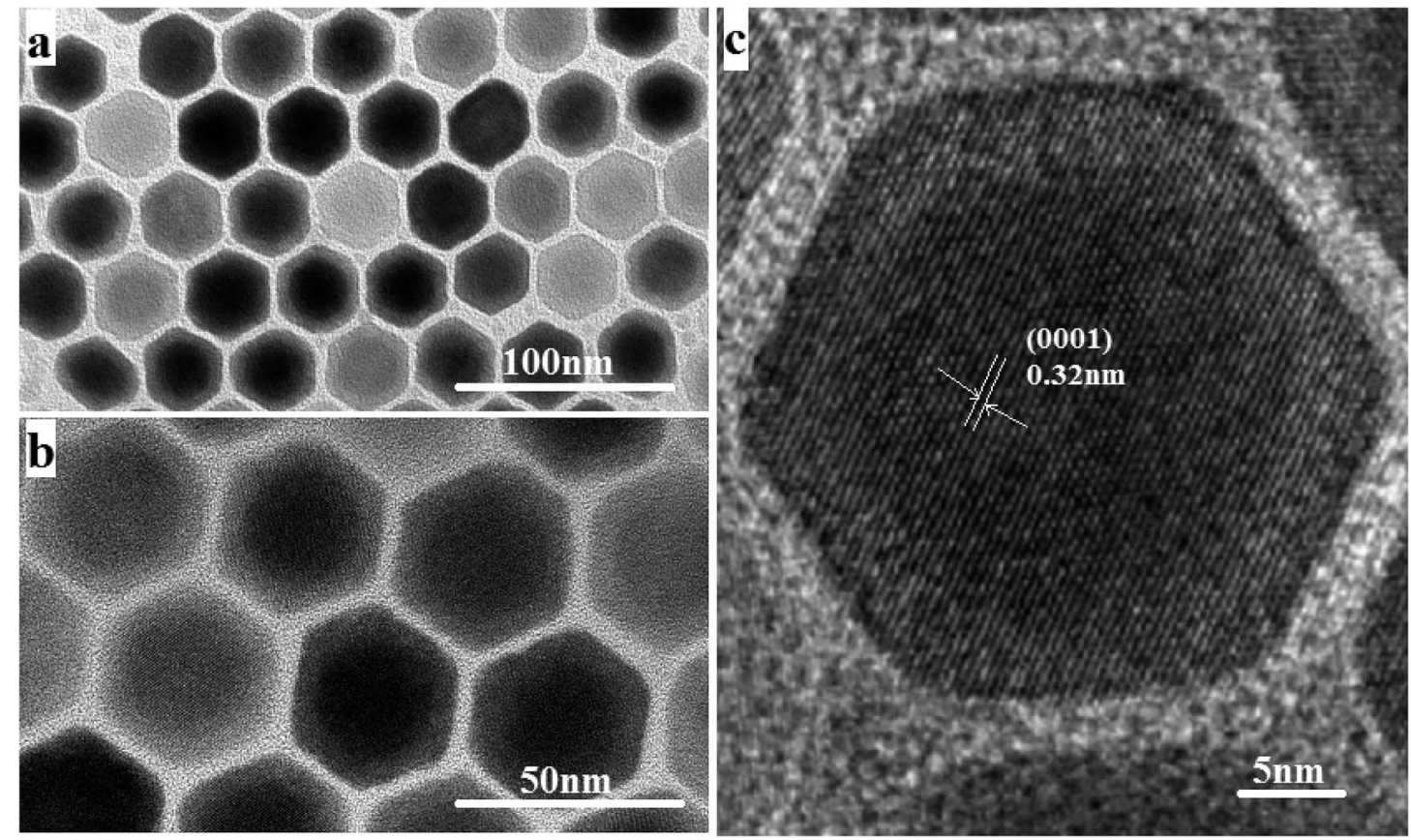

Fig. 1 ( $a$ and b) TEM images of $\mathrm{NaGdF}_{4}: 18 \% \mathrm{Yb}^{3+}, 2 \% \mathrm{Er}^{3+} \mathrm{aNaYF}_{4}$ core/shell nanoparticles. (c) The corresponding high-resolution TEM images. 


\section{Result and discussion}

The size and morphology of the as-synthesized upconversion nanoparticles were characterized by the TEM and HRTEM. It can be observed from Fig. 1(a) and (b) that the $\mathrm{NaGdF}_{4}$ :- $^{-}$ $\mathrm{Yb}^{3+}, \mathrm{Er}^{3+} @ \mathrm{NaYF}_{4}$ nanoparticles have a clear core/shell configuration and possess an average diameter of $32 \mathrm{~nm}$, typical hexagonal crystal facets and good crystallinity. From the HRTEM image (Fig. 1(c)), the lattice fringes can be clearly distinguished on an individual particle, and the distances between the lattice fringes were measured to be $0.32 \mathrm{~nm}$ along the (0001) orientation in the core and shell.

The composition of the core and the shell were determined by the energy dispersive spectrum (EDS) (Fig. 2). The EDS analysis showed that the lanthanide elements Gd, Yb, Er and Y were co-doped in the $\mathrm{NaF}$ crystal to form the $\mathrm{NaGdF}_{4}$ :$\mathrm{Yb}^{3+}, \mathrm{Er}^{3+} @ \mathrm{NaYF}_{4}$ core/shell upconversion nanoparticles, which was also supported by the TEM characterization and the upconversion emission spectrum under $980 \mathrm{~nm}$ excitation, which will be discussed further. It is clear from Table 1 that the concentration of Gd element in the core area is more than two times that in the shell area. The core-shell nanoparticle is so small that it is hard to precisely select an area only located at the shell for EDS (see Fig. 2). As a result, the signal of the element Gd arises in the energy dispersive spectrum. In addition, the $\mathrm{NaGdF}_{4}: \mathrm{Yb}^{3+}, \mathrm{Er}^{3+}$ core was fully covered by the $\mathrm{NaYF}_{4}$ shell. Thus, it is inevitable that the EDS signal of element $\mathrm{Yb}$ arises in the designated core area.

It can be easily concluded from the X-ray diffraction (XRD) spectrum in Fig. 3 that the $\mathrm{NaGdF}_{4}: \mathrm{Yb}^{3+}, \mathrm{Er}^{3+} @ \mathrm{NaYF}_{4}$ core/shell nanoparticles possess the hexagonal crystal phase, which agrees

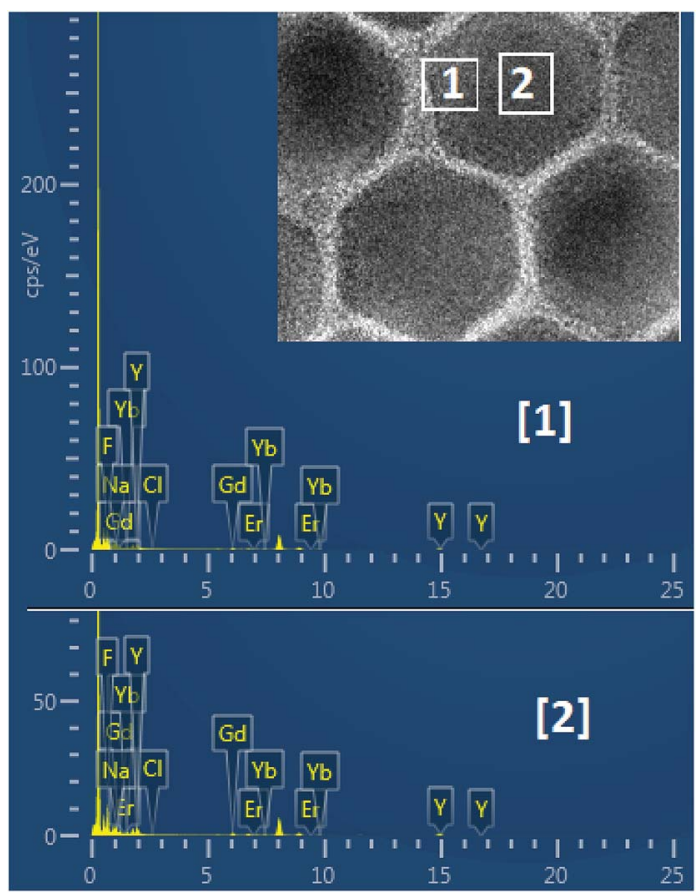

Fig. 2 Energy dispersive spectrum (EDS) of $\mathrm{NaGdF}_{4}: \mathrm{Yb}^{3+}, \mathrm{Er}^{3+} \mathrm{aNaYF}_{4}$ core/shell nanoparticles.

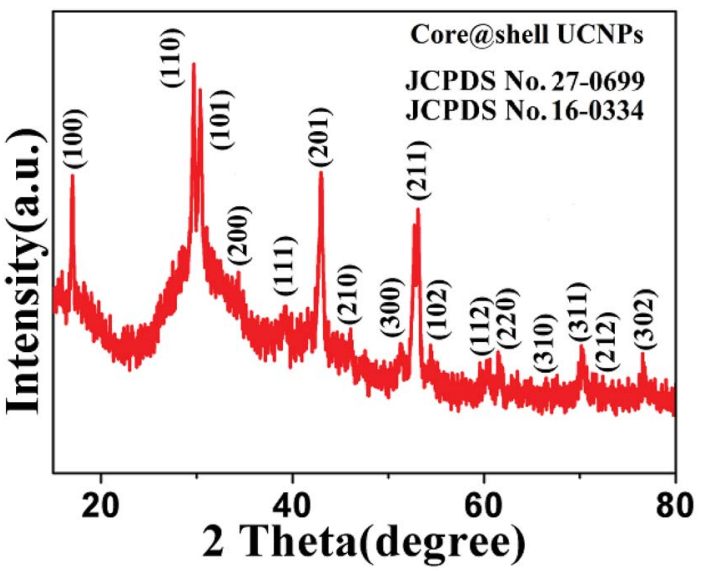

Fig. 3 XRD spectrum of $\mathrm{NaGdF}_{4}: 18 \% \mathrm{Yb}^{3+}, 2 \% \mathrm{Er}^{3+} \mathrm{aNaYF}_{4}$ core/shell particles.

with the result obtained through HRTEM in Fig. 1. The upconversion fluorescence spectrum of $\mathrm{NaGdF}_{4}$ :$\mathrm{Yb}^{3+}, \mathrm{Er}^{3+} @ \mathrm{NaYF}_{4}$ core/shell and bare $\mathrm{NaGdF}_{4}: 18 \% \mathrm{Yb}^{3+}, 2 \% \mathrm{Er}^{3+}$ nanoparticles in CGT under the $980 \mathrm{~nm}$ laser excitation are shown in Fig. 4. The emission bands can be easily assigned to the transitions within the $4 \mathrm{f}-4 \mathrm{f}$ levels of the $\mathrm{Er}^{3+}$ ions. The spectra of the $\mathrm{NaGdF}_{4}: \mathrm{Yb}^{3+}, \mathrm{Er}^{3+} @ \mathrm{NaYF}_{4}$ core/shell nanoparticles exhibits three distinct emission bands from $\mathrm{Er}^{3+}$ ions that are centered at $408 \mathrm{~nm}, 540 \mathrm{~nm}$, and $658 \mathrm{~nm}$, corresponding to emission levels ${ }^{2} \mathrm{H}_{9 / 2},{ }^{4} \mathrm{~S}_{3 / 2}$, and ${ }^{4} \mathrm{~F}_{9 / 2}$, respectively. The luminescence appears green to naked eye due to the combination of weak violet, intense green and weak red emissions from the $\mathrm{Er}^{3+}$ ion.

The possible upconversion excitation and emission pathways between the $\mathrm{Er}^{3+} / \mathrm{Yb}^{3+}$ ions have been well-known. In the case of $\mathrm{NaGdF}_{4}: 18 \% \mathrm{Yb}^{3+}, 2 \% \mathrm{Er}^{3+}$, an initial energy transfer from an $\mathrm{Yb}^{3+}$ ion in the ${ }^{2} \mathrm{~F}_{5 / 2}$ state to an $\mathrm{Er}^{3+}$ ion populates the ${ }^{4} \mathrm{I}_{11 / 2}$ level of the $\mathrm{Er}^{3+}$ ion. A second $980 \mathrm{~nm}$ photon or energy transfer from an $\mathrm{Yb}^{3+}$ ion to the $\mathrm{Er}^{3+}$ ion can then populate the ${ }^{4} \mathrm{~F}_{7 / 2}$ level of the $\mathrm{Er}^{3+}$ ion.

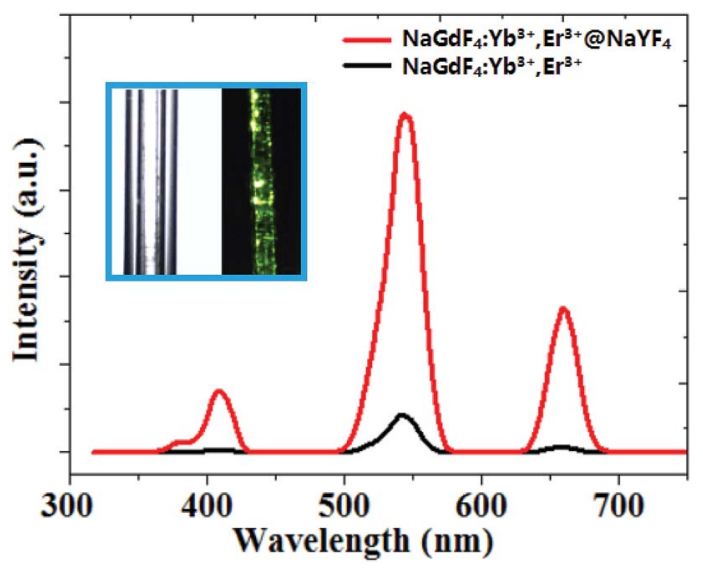

Fig. 4 Room temperature upconversion emission spectrum of core/ shell $\mathrm{NaGdF}_{4}: 18 \% \mathrm{Yb}^{3+}, 2 \% \mathrm{Er}^{3+} \mathrm{aNaYF}_{4}$ and bare $\mathrm{NaGdF}_{4}: 18 \% \mathrm{Yb}^{3+}, 2 \%$ $\mathrm{Er}^{3+}$ nanoparticles. The inset: the photograph of core/shell UCNPS dispersed in CGT under the $0.08 \mathrm{~W} \mathrm{~cm}^{-2}$ laser power at $980 \mathrm{~nm}$ excitation. 
Table 1 The element distribution determined by EDS

\begin{tabular}{|c|c|c|c|c|c|c|}
\hline $\mathrm{F}$ & $\mathrm{Cl}$ & $\mathrm{Na}$ & $\mathrm{Y}$ & Gd & $\mathrm{Yb}$ & $\mathrm{Er}$ \\
\hline \multicolumn{7}{|c|}{ Site 1. elements (at\%) } \\
\hline 76.7 & 0.2 & 10.0 & 10.1 & 1.9 & 1.1 & 0.0 \\
\hline \multicolumn{7}{|c|}{ Site 2. elements (at\%) } \\
\hline 76.3 & 0.2 & 8.2 & 9.8 & 4.1 & 1.4 & 0.0 \\
\hline
\end{tabular}

The electrons in the ${ }^{4} \mathrm{~F}_{7 / 2}$ level of $\mathrm{Er}^{3+}$ ion can relax nonradiatively (without emission of photons) to the ${ }^{4} S_{3 / 2}$ levels to generate green emissions by the transition ${ }^{4} \mathrm{~S}_{3 / 2} \rightarrow{ }^{4} \mathrm{I}_{15 / 2}$. Alternatively, the $\mathrm{Er}^{3+}$ ion can further relax and populate the ${ }^{4} \mathrm{~F}_{9 / 2}$ level, leading to the red emission from the transition ${ }^{4} \mathrm{~F}_{9 / 2} \rightarrow{ }^{4} \mathrm{I}_{15 / 2}$. The ${ }^{4} \mathrm{~F}_{9 / 2}$ level may also be populated from the ${ }^{4} \mathrm{I}_{13 / 2}$ level of the $\mathrm{Er}^{3+}$ ion by absorption of a $980 \mathrm{~nm}$ photon or energy transfer from an $\mathrm{Yb}^{3+}$ ion, with the ${ }^{4} \mathrm{I}_{13 / 2}$ state being initially populated via the nonradiative ${ }^{4} \mathrm{I}_{11 / 2} \rightarrow{ }^{4} \mathrm{I}_{13 / 2}$ relaxation.

The detection mechanisms of Dox were investigated based on the fluorescence and absorption spectra and the intensity ratio of green to red emissions in Fig. 5. As can be clearly seen, the main absorption band of doxorubicin overlaps with the green light of the $\mathrm{NaGdF}_{4}: 18 \% \mathrm{Yb}^{3+}, 2 \% \mathrm{Er}^{3+} @ \mathrm{NaYF}_{4}$ core/shell particles. Thus, the green emission of UCNPs can be efficiently absorbed by Dox. It is noted that Dox can also absorb red emission, but with a lower absorption efficiency. The fluorescence spectra were normalized by the red emission peak. ${ }^{\mathbf{6} 21}$ This band overlap can be used for Dox detection.

Furthermore, the detection of doxorubicin in mice blood was investigated. Healthy mice were injected with different concentrations of doxorubicin $\left(0 \mu \mathrm{g} \mathrm{mL} L^{-1}, 20 \mu \mathrm{gL}^{-1}, 50 \mu \mathrm{g} \mathrm{mL}{ }^{-1}, 70\right.$ $\mu \mathrm{g} \mathrm{mL}^{-1}$, and $\left.100 \mu \mathrm{g} \mathrm{mL}^{-1}\right)$. The as-prepared UCNPs@CGT bioprobe was inserted into the mice through one port of the $y$ type optical fiber, and the other two ports were connected to a $980 \mathrm{~nm}$ laser and a fluorescence spectrometer. This approach provided real-time detection of Dox. We can clearly see in Fig. 5 that as the concentration of doxorubicin increased from $0 \mu \mathrm{g}$ $\mathrm{mL}^{-1}$ to $100 \mu \mathrm{g} \mathrm{mL}^{-1}$, the upconversion fluorescence intensity of green-to-red emission decreased linearly. At the same time, we can see that with the increase in the concentration of doxorubicin, the emission peak of the green light shifted from the original $540 \mathrm{~nm}$ to $524 \mathrm{~nm}$ along with an increase in the peak height. This can be explained by the collective influence of Dox and blood absorption. Blood containing Dox presents a remarkable absorption peak at $\sim 540 \mathrm{~nm}$, which is relatively weak at $524 \mathrm{~nm}$ (without Dox). Thus, the increase in Dox content leads to the decrease in overall intensity of green light, while the constant absorption of light by blood gradually plays a more important role for tuning the shape of green emission peaks of the probe. As a result, it is observed that the green peak shifts from 540 to $524 \mathrm{~nm}$ due to the coexistence of Dox and blood absorptions.

These observations revealed that the absorption efficiency of Dox for the emission from the ${ }^{4} \mathrm{~S}_{3 / 2}$ state is much higher than that from the ${ }^{2} \mathrm{H}_{11 / 2}$ state. The IGVRE for different concentrations of Dox is shown in Fig. 5(b), from which it can be concluded that during the detection of Dox ranging from $0-100 \mu \mathrm{g} \mathrm{mL} \mathrm{m}^{-1}$, the real detection results fluctuate mildly around the black dot (the average value), and the overall measurement errors (absolute value) were below $3.5 \%$. It can be seen that when Dox was not injected into mice, the detection results showed quite a small error of about $-0.16-0.14 \%$. Thus, the tested environment showed negligible influence on the emission behavior of the proposed fluorescent probe. However, when Dox was injected into mice, the tested environment encountered by the fluorescent probe will be changed. Then, the emission behavior will be modulated due to the spectrum overlap. When the concentration of Dox increased to $20 \mu \mathrm{g} \mathrm{mL}{ }^{-1}$, the real detection results showed a measurement error of $-1.99-1.95 \%$, which was larger than that without Dox. This error was probably attributed to the dynamic metabolism and residue of Dox. With the further increase in Dox concentration, the overall measurement errors were all below $3.5 \%$. These results indicated that the proposed detection approach can be employed for Dox detection in vivo. It also shows
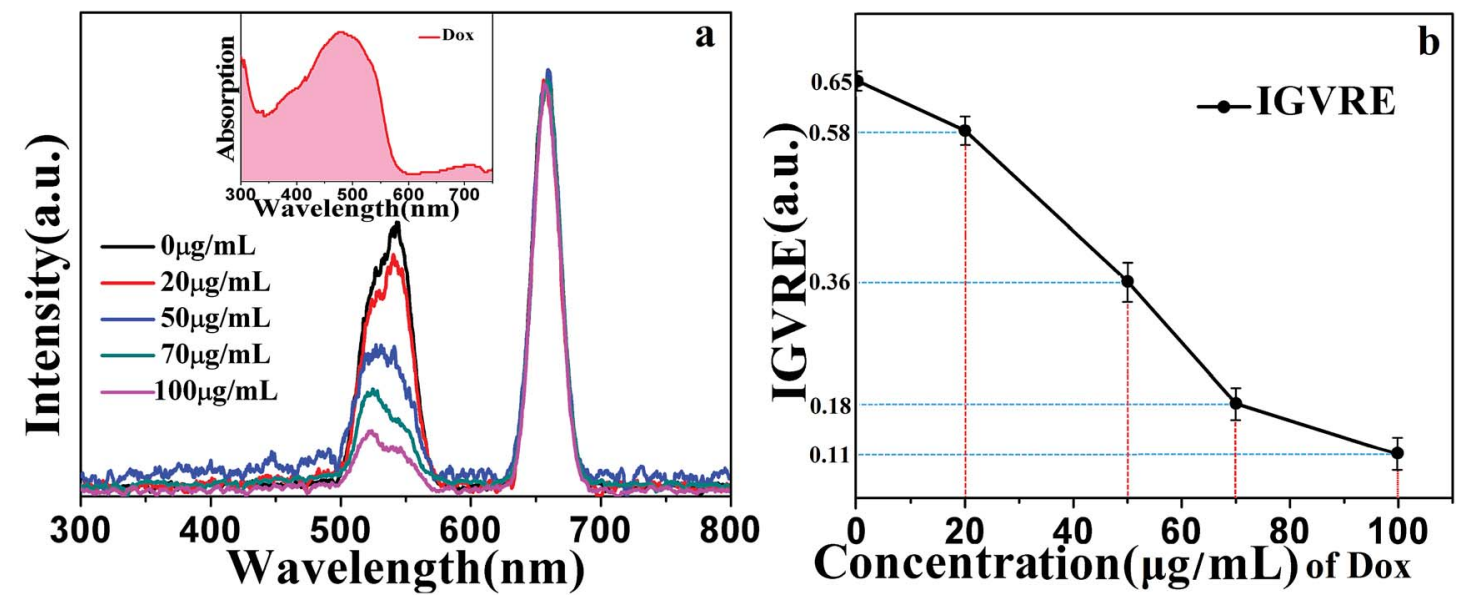

Fig. 5 (a) Room-temperature upconversion fluorescence spectra of $\mathrm{NaGdF}_{4}: 18 \% \mathrm{Yb}^{3+}, 2 \% \mathrm{Er}^{3+} \mathrm{aNaYF}_{4}$ core/shell particles with different concentrations of doxorubicin $\left(0 \mu \mathrm{g} \mathrm{mL}^{-1}, 20 \mu \mathrm{g} \mathrm{mL}^{-1}, 50 \mu \mathrm{g} \mathrm{mL}^{-1}, 70 \mu \mathrm{g} \mathrm{mL}^{-1}\right.$, and $100 \mu \mathrm{g} \mathrm{mL}^{-1}$ ) under the $980 \mathrm{~nm}$ excitation with power intensity of $0.08 \mathrm{~W} \mathrm{~cm}^{-2}$ simultaneously. The inset shows the absorption spectrum of doxorubicin. (b) The ratio of simultaneous green and red emission intensity. 

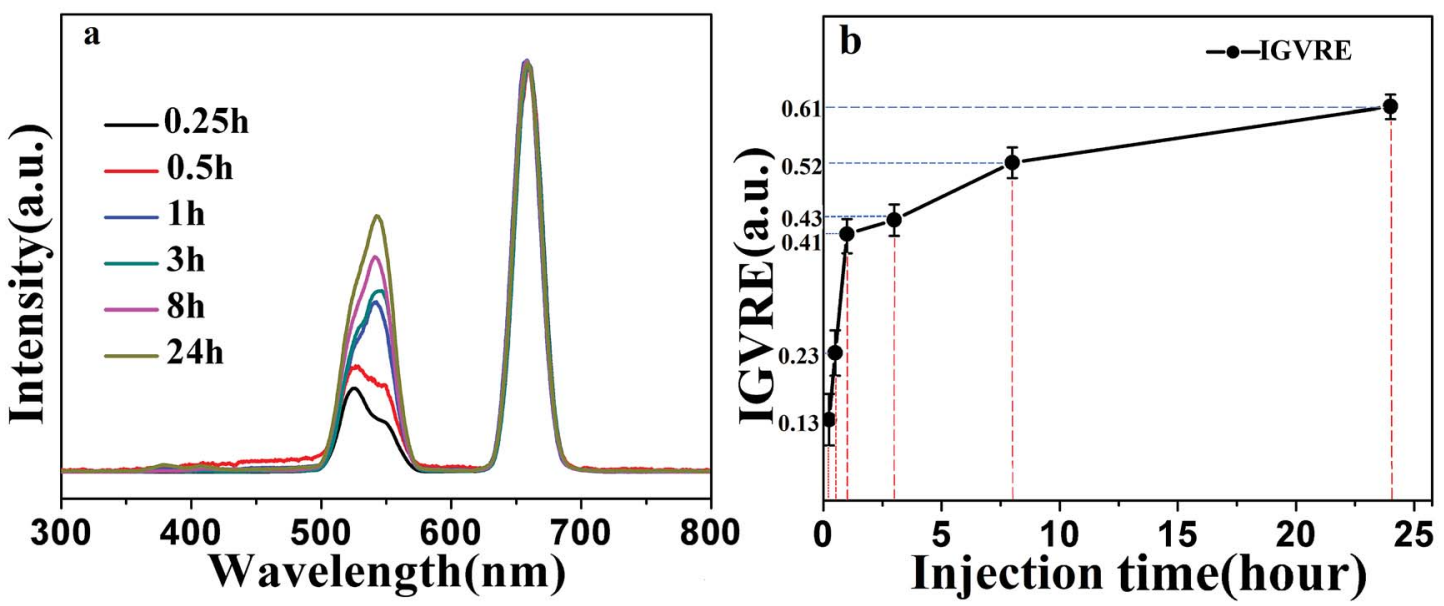

Fig. 6 (a) Evolution of the fluorescence intensity of core/shell UCNPs with the same concentration at different time points under 980 nmexcitation with power intensity of $0.08 \mathrm{~W} \mathrm{~cm}^{-2}$. (b) The ratio of green and red emission intensity at the different time points.

that the repeatability of the detection method is very good. This simple Dox detection mechanism can be considered as the radiation energy absorption between Dox and the $\mathrm{NaGdF}_{4}$ :$\mathrm{Yb}^{3+}, \mathrm{Er}^{3+} @ \mathrm{NaYF}_{4}$ core/shell nanoparticles.

The above discussion mainly focused on detecting the concentration of Dox in vivo. Next, we studied the continuous detection of Dox in living mice after $2 \mathrm{~mL}$ solution of $100 \mu \mathrm{g}$ $\mathrm{mL}^{-1}$ Dox was injected, as shown in Fig. 6(a). The fluorescence spectra were normalized by the red emission peak. After $15 \mathrm{~min}$ post-injection, Dox began to act on living cells. The ratio between the $524 \mathrm{~nm}$ green emission and the $658 \mathrm{~nm}$ red emission is very small, indicating high Dox concentration. After
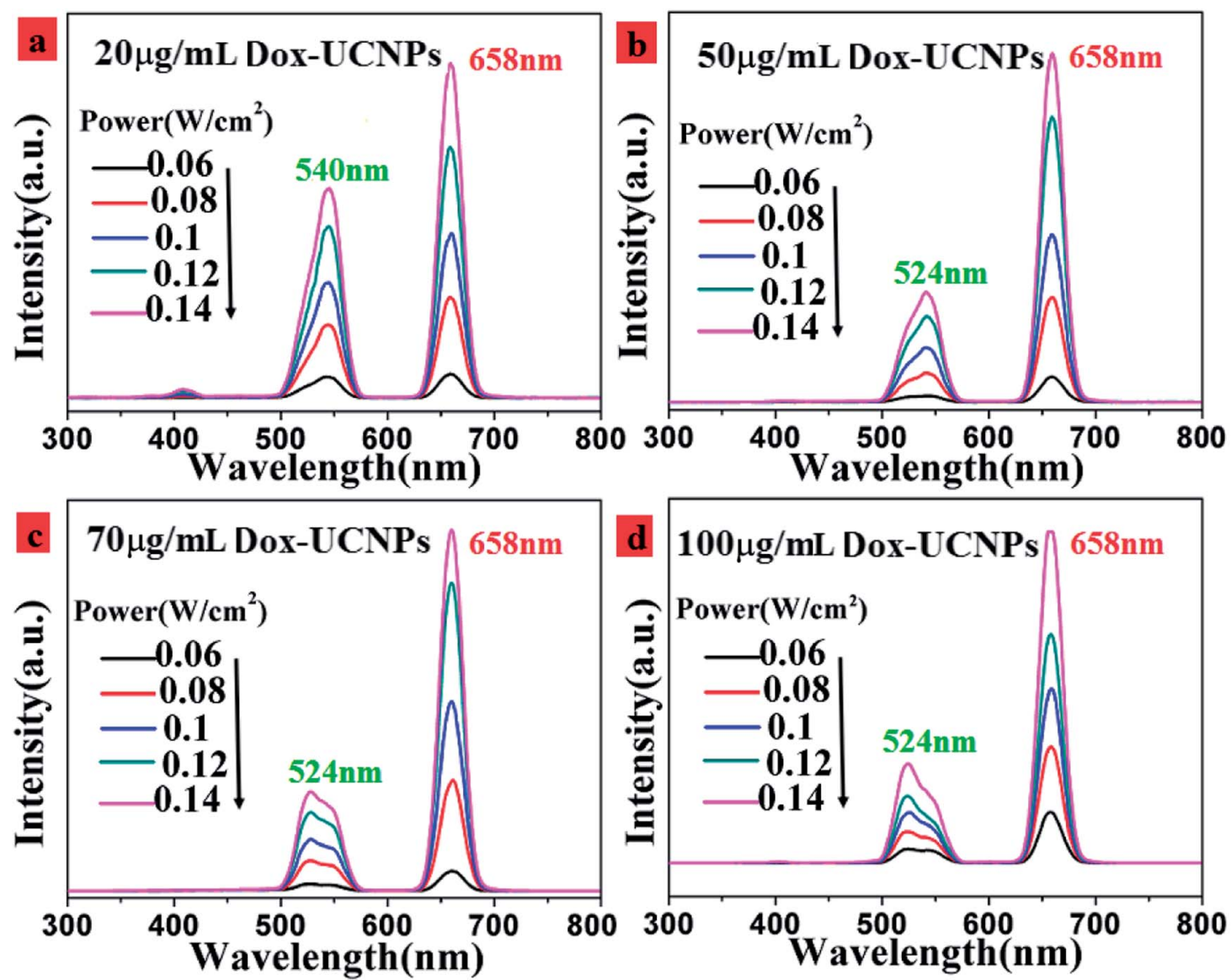

Fig. $7 \mathrm{UC}$ luminescence spectra of $\mathrm{NaGdF}_{4}: 18 \% \mathrm{Yb}^{3+}, 2 \% \mathrm{Er}^{3+} \mathrm{aNaYF}_{4}$ core/shell particles in the with different concentrations of $\mathrm{Dox}$. (a) $20 \mu \mathrm{g} \mathrm{mL}^{-1}$; (b) $50 \mu \mathrm{g} \mathrm{mL}^{-1}$; (c) $70 \mu \mathrm{g} \mathrm{mL}^{-1}$; (d) $100 \mu \mathrm{g} \mathrm{mL}^{-1}$ at $980 \mathrm{~nm}$-excitation under different laser powers. 
$30 \mathrm{~min}$, the red-to-green emission ratio increased slightly, revealing a decreased concentration of doxorubicin. However, one hour after the injection, the red-green emission ratio increased rapidly, and the green emission center shifted from the original $524 \mathrm{~nm}$ to $540 \mathrm{~nm}$. This indicates that a large amount of doxorubicin was decomposed or eliminated from the body after one hour post-injection. In the next 3-8 hours, the fluorescence intensity increased slowly and nearly plateaued. This proved that the anti-tumor drug is highly degradable. In addition, it can be seen in Fig. 6(b) that the IGVRE increased quickly in the first $1 \mathrm{~h}$, which indicated that the metabolism of Dox was quite apparent in the first hour. In addition, the measurement errors were also noteworthy (about 2.3-4.8\%). This can be explained by the dynamic metabolism and residual Dox. The variation in IGVRE increased gently after 1-8 h post Dox injection. Thus, the measurement error turned to be smaller and more stable, with a range of around $2 \%$, which corresponds to a stable metabolism and residue of Dox. After $24 \mathrm{~h}$, the IGVRE reaches a high average value of about 0.61 , which was quite close to the IGVRE of 0.65 in the above analysis with no Dox injection. This result indicated that very a small amount of Dox remains in the mouse body after $24 \mathrm{~h}$ postinjection, and the measurement error was lowered to -0.62$0.57 \%$, which was in agreement with the former discussion. This can be considered as an opposite process to the discussion and phenomenon observed in Fig. 5(a). Thus, the overall recovered green emission and the slight peak shift from 524 to $540 \mathrm{~nm}$ confirmed the excretion of Dox. Under the same conditions, for a large number of detections, the intensity ratio changes within five percent of the original values.

In order to investigate the upconversion luminescence mechanism in this Dox-UCNPs composite system, the excitation power dependence of green and red emission bands were measured, as shown in Fig. 7. The integral UCL intensity for both red and green emission of the core-shell nanoparticles composite with different concentrations of Dox increased when the incident laser power was enhanced (Fig. 7(a)-(d)). It is clear that the red emission centered at $658 \mathrm{~nm}$ and the green emission centered at $540 \mathrm{~nm}$ from the $\mathrm{Er}^{3+}$ ions belong to the two photon upconversion processes. Upconversion emission intensities of the $\mathrm{NaGdF}_{4}: 18 \% \mathrm{Yb}^{3+}, 2 \% \mathrm{Er}^{3+}$ nanoparticles demonstrated quadratic power dependencies at low excitation densities. It seems that two photon upconversion processes were involved in the $658 \mathrm{~nm}$ red and $540 \mathrm{~nm}$ green emissions.

Subsequently, we demonstrate that this detection method is clearly different from the technique involving the direct usage of green and red light beams. As demonstrated in Fig. 8(a), it is clear that in case of the as-prepared UCNPs probe irrespective of the depth of the injection, the collected emission light has constant intensity. This is because the emission depended only on the length of the UCNPs in the probe tube and was independent of the injection depth of the probe. As long as the UCNPs probe is fully inserted into the blood vessel of the living mice, any further injection depth will not change the emission spectrum of the UCNP. This position independence provided some advantages, such as low detection error. However, the findings are completely different when the green and red

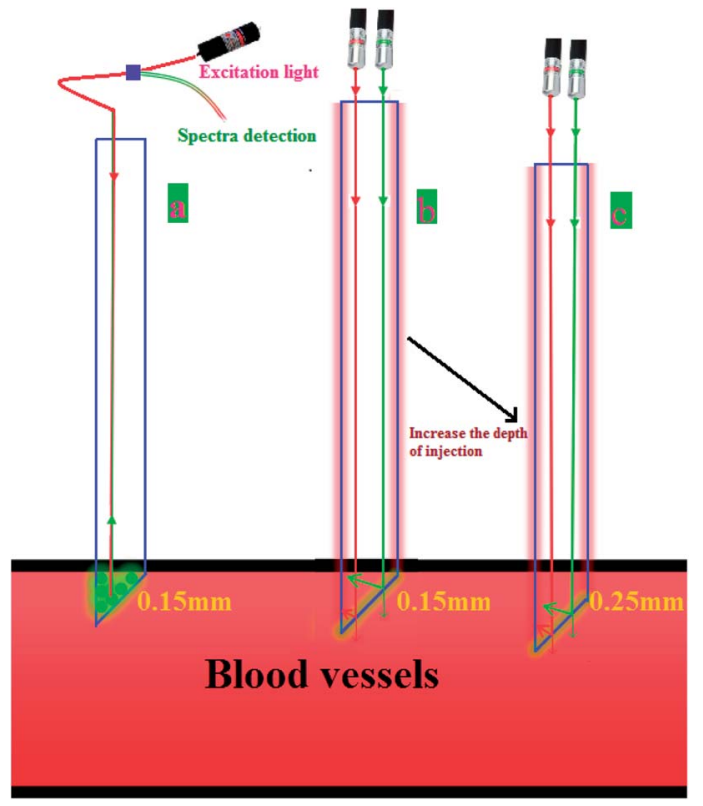

Fig. 8 Comparison of residual detection of doxorubicin using a UCNPs probe with that using conventional methods. (a) UCNPs probe insertion into blood vessels at $0.15 \mathrm{~mm}$ (b) the traditional method was used to detect Dox insertion into blood vessels at 0.15 $\mathrm{mm}$. (c) The traditional method was used to detect Dox insertion into blood vessels at $0.25 \mathrm{~mm}$

detection beams were directly used (Fig. 8(b) and (c)). The intensity collected is highly dependent on the injecting depth, thus leading to intrinsic deviation. As a result, the model demonstrated in this study is a viable and efficient system for rapid and precise detection of Dox in vivo.

\section{Conclusions}

In conclusion, core-shell $\mathrm{NaGdF}_{4}: \mathrm{Yb}^{3+}, \mathrm{Er}^{3+} @ \mathrm{NaYF}_{4}$ nanoparticles were synthesized by the solvothermal method. These core-shell $\mathrm{NaGdF}_{4}: \mathrm{Yb}^{3+}, \mathrm{Er}^{3+} @ \mathrm{NaYF}_{4}$ nanoparticle exhibited green and red upconversion luminescence under the excitation power density of a single wavelength infrared light source (980 $\mathrm{nm})$. We found that the intensity ratio of green and red emission bands of the core/shell $\mathrm{NaGdF}_{4}: \mathrm{Yb}^{3+}, \mathrm{Er}^{3+} @ \mathrm{NaYF}_{4}$ nanoparticles were sensitive to the concentration of Dox in the blood and showed an almost linear relationship, so that the content of Dox can be accordingly controlled. A high-precision and realtime probe was fabricated based on upconversion nanoparticles for detecting Dox. This probe can not only accurately detect the concentration of doxorubicin in animal blood, but also assess the anti-cancer drug on human cell cytotoxicity. More importantly, based on this proposed detection approach, the problem of difficult excretion of nanoparticles from the living body and the leakage of the nanoparticles in blood, as reported for the previous fluorescence resonance energy transfer method, can be efficiently avoided. The as-fabricated probe is reusable and inexpensive with simple operation and real-time rapid detection. We expect this UCNPs probe to open up new situations for medical testing and cytotoxicity assessment. 


\section{Live subject statement}

All experiments were performed in compliance with relevant laws or guidelines, and followed institutional guidelines. All animal procedures were performed in accordance with the Guidelines for Care and Use of Laboratory Animals of Hunan University of Science and Technology and experiments were approved by the Laboratory Animal Welfare and Ethics Committee CALAS.

\section{Conflicts of interest}

No conflict of interest exits in the submission of this manuscript, and manuscript is approved by all authors for publication.

\section{Acknowledgements}

This study was funded by the National Natural Science Foundations of China (Grant No. 61675067, 61575062 and 51675174) and the Scientific Research Fund of Hunan Province Education Department (Grant No. 16C0627 and 16A072).

\section{References}

1 H. Goesmann and C. Feldmann, Nanoparticulate Functional Materials, Angew. Chem., Int. Ed., 2010, 49, 1362-1395.

2 H. S. Mader, P. Kele, S. M. Saleh and O. S. Wolf beis, Upconverting luminescent nanoparticles for use in bioconjugation and bioimaging, Curr. Opin. Chem. Biol., 2010, 14, 582.

3 Y. X. Liu, D. S. Wang, L. L. Li, Q. Peng and Y. D.Li, Energy upconversion in lanthanide-doped core/porous-shell nanoparticles, Inorg. Chem., 2014, 53, 3257.

4 F. Wang, Y. Han, C. S. Lim, Y. H. Lu, J. Xu, et al. Simultaneous phase and size control of upconversion nanocrystals through lanthanide doping, Nature, 2010, 463, $1061 \mathrm{e} 5$.

5 Z. H. Chen, X. F. Wu, S. G. Hu, P. Hu, H. Y. Yan, Z. J. Tang and Y. X. Liu, Upconversion $\mathrm{NaLuF}_{4}$ fluorescent nanoprobes for jellyfish cell imaging and irritation assessment of organic dyes, J. Mater. Chem. C, 2015, 3, 6067-6076.

6 J. C. Boyer, L. A. Cuccia and J. A. Capobianco, Synthesis of colloidal upconverting $\mathrm{NaYF}_{4}: \mathrm{Er}^{3+} / \mathrm{Yb}^{3+}$ and $\mathrm{Tm}^{3+} / \mathrm{Yb}^{3+}$ monodisperse nanocrystals, Nano Lett., 2007, 7, 847.

7 F. Wang, D. Banerjee, Y. S. Liu, X. Y. Chen and X. G. Liu, Upconversion nanoparticles in biological labeling, imaging, and therapy, Analyst, 2010, 135, 1797-2160.

8 K. Song, L. J. Tian, X. G. Kong, K. Liu, Q. B. Zhang, C. Du, et al. Preparation, characterization and specific biological labeling of silica coated upconversion fluorescent nanocrystals, Spectrosc. Spectral Anal., 2010, 30, $133 \mathrm{e} 6$.

9 S. Jiang and Y. Zhang, Upconversion nanoparticle-based FRET system for study of siRNA in live cells, Langmuir, 2010, 26, 6689e94.
10 H. P. Zhou, C. H. Xu, W. Sun and C. H. Yan, Clean and flexible modification strategy for carboxyl/aldehydefunctionalized upconversion nanoparticles and their optical applications, Adv. Funct. Mater., 2009, 19, 3892e900.

11 M. Wang, C. C. Mi, Y. X. Zhang, J. L. Liu, F. Li, C. B. Mao, et al. NIR-responsive silica coated NaYbF4:Er/Tm/Ho upconversion fluorescent nanoparticles with tunable emission colors and their applications in immunolabeling and fluorescent imaging of cancer cells, J. Phys. Chem. C, 2009, 113, $19021 \mathrm{e} 7$.

12 H. S. Qian, H. C. Guo, P. C. L. Ho, R. Mahendran and Y. Zhang, Mesoporous-silica-coated upconversion fluorescent nanoparticles for photodynamic therapy, Small, 2009, 5, 2285e90.

13 R. J. Strife, I. Jardine and M. Colvin, Analysis of the anticancer drugs VP 16-213 and VM 26 and their metabolites by high-performance liquid chromatography, $J$. Chromatogr. B: Biomed. Sci. Appl., 1980, 182(2), 211-220.

$14 \mathrm{M}$. Haase and H. Schafer, Upconverting Nanoparticles, Angew. Chem., Int. Ed., 2011, 50, 5808-5829.

15 M. Wang, C. C. Mi, W. X. Wang, C. H. Liu, Y. F. Wu, Z. R. Xu, C. B. Mao and S. K. Xu, Immunolabeling and NIR excited fluorescent imaging of HeLa cells by using $\mathrm{NaYF}_{4}: \mathrm{Yb}, \mathrm{Er}$ upconversion nanoparticles, ACS Nano, 2009, 3, 1580-1586.

16 Q. Liu, T. S. Yang, W. Feng and F. Y. Li, Blue-Emissive Upconversion Nanoparticles for Low-Power-Excited Bioimaging in vivo, J. Am. Chem. Soc., 2012, 134, 5390-5397.

17 R. M. Rodríguez, S. Fischer, A. Ivaturi, B. Froehlich, K. W. Krämer, K. J. C. Goldschmidt, B. S. Richards and A. Meijerink, Highly Efficient IR to NIR Upconversion in Gd2O2S: Er3+ for Photovoltaic Applications, Chem. Mater., 2013, 25, 1912-1921.

18 O. Spadiut, F. M. Ibatullin, J. Peart, F. Gullfot, C. M. Fleites, M. Ruda, C. L. Xu, G. Sundqvist, G. J. Davies and H. Brumer, Building Custom Polysaccharides in vitro with an Efficient, Broad-Specificity Xyloglucan Glycosynthase and a Fucosyltransferase, J. Am. Chem. Soc., 2011, 133, 1089210900.

19 S. S. Cui, D. Y. Yin, Y. Q. Chen, Y. F. Di, H. Y. Chen, Y. X. Ma, S. Achilefu and Y. Q. Gu, In Vivo Targeted Deep-Tissue Photodynamic Therapy Based on Near-Infrared Light Triggered Upconversion Nanoconstruct, ACS Nano, 2013, 7, 676-688.

20 H. T. Wong, M. K. Tsang, C. F. Chan, K. L. Wong, B. Fei and J. H. Hao, In vitro cell imaging using multifunctional small sized $\mathrm{KGdF}_{4}: \mathrm{Yb}^{3+}, \mathrm{Er}^{3+}$ upconverting nanoparticles synthesized by a one-pot solvothermal process, Nanoscale, 2013, 5, 3465-3473.

21 Z. Deutsch, L. Neeman and D. Oron, Luminescence upconversion in colloidal double quantum dots, Nat. Nanotechnol., 2013, 146, 649-653.

22 J. Yao, M. Yang and Y. X. Duan, Chemistry, Biology, and Medicine of Fluorescent Nanomaterials and Related Systems: New Insights into Biosensing, Bioimaging, Genomics, Diagnostics, and Therapy, Chem. Rev., 2014, 114, 6130-6178. 
23 S. Das, A. M. Powe, G. A. Baker, B. Valle, B. E. Zahab, H. Q. Sintim, M. Lowry, S. O. Fakayode, M. E. McCarroll, G. Patonay, M. Li, R. M. Strongin, M. L. Geng and I. M. Warner, Molecular Fluorescence, Phosphorescence, and Chemiluminescence Spectrometry, Anal. Chem., 2012, 84, 597-625.

24 F. Wang, R. R. Deng and X. G. Liu, Preparation of core-shell NaGdF4 nanoparticles doped with luminescent lanthanide ions to be used as upconversion-based probes, Nat. Protoc., 2014, 111, 1634-1644.

25 K. Lee, S. W. Park, M. J. Ko, K. Kim and N. G. Park, Selective positioning of organic dyes in a mesoporous inorganic oxide film, Nat. Mater., 2009, 2475, 665-671.

26 M. F. Bennewitz, T. L. Lobo, M. K. Nkansah, G. Ulas, G. W. Brudvig and E. M. Shapiro, Biocompatible and $\mathrm{pH}-$ Sensitive PLGA Encapsulated MnO Nanocrystals for Molecular and Cellular MRI., ACS Nano, 2011, 5, 3438-3446.

27 H. T. Wong, F. Vetrone, R. Naccache, H. L. W. Chan, J. H. Hao and J. A. Capobianco, Water dispersible ultrasmall multifunctional KGdF4:Tm3+,Yb3+ nanoparticles with near-infrared to near-infrared upconversion, J. Mater. Chem., 2011, 21, 16589-16596.

28 Y. M. Zhang, M. Jeon, L. J. Rich, H. Hong and J. M. Geng, Non-invasive multimodal functional imaging of the intestine with frozen micellar naphthalocyanines, Nat. Nanotechnol., 2014, 130, 631-638.

29 J. Zhou, Z. Liu and F. Y. Li, Upconversion nanophosphors for small-animal imaging. Sandberg, Single-cell RNA-seq reveals dynamic, random monoallelic gene expression in mammalian cells, Science, 2014, 343, 193-196.

30 K. B. Male, B. Lachance, S. Hrapovic, G. Sunahara and J. H. T. Luong, Assessment of Cytotoxicity of Quantum Dots and Gold Nanoparticles Using Cell-Based Impedance Spectroscopy, Anal. Chem., 2008, 80, 5487-5493.

31 A. Shvedova, V. Castranova, E. Kisin, D. S. Berry, A. Murray, V. Gandelsman, A. Maynard and P. Baron, Exposure to Carbon Nanotube Material: Assessment of Nanotube
Cytotoxicity using Human Keratinocyte Cells, J. Toxicol. Environ. Health, 2003, 20, 1909-1926.

32 D. J. Dexter, Theory of Concentration Quenching in Inorganic Phosphors, J. Chem. Phys., 1953, 21, 836.

33 K. E. Sapsford, L. Berti and I. L. Medintz, Materials for Fluorescence Resonance Energy Transfer Analysis: Beyond Traditional Donor-Acceptor Combinations, Angew. Chem., Int. Ed., 2006, 45, 4562-4589.

34 Q. Deng, D. Ramskold, B. Reinius and R. Sandberg, Singlecell RNA-seq reveals dynamic, random monoallelic gene expression in mammalian cells, Science, 2014, 343, 193-196.

35 M. Y. Berezin and S. Achilefu, fluorescence lifetime measurements and biological imaging, Chem. Rev., 2010, 110, 2641.

36 Q. Liu, J. J. Peng, L. N. Sun and F. Y. Li, High-Efficiency Upconversion Luminescent Sensing and Bioimaging of $\mathrm{Hg}$ (II) by Chromophoric Ruthenium Complex-Assembled Nanophosphors, ACS Nano, 2011, 5, 8040-8048.

37 W. H. Wu, S. M. Ji, W. T. Wu, J. Y. Shao, H. M. Guo, T. D. James and J. Z. Zhao, Ruthenium(II) Polyimine Coumarin Light Harvesting Molecular Arrays: Design Rationale and Application for Triplet-Triplet-AnnihilationBased Upconversion, Chem.-Eur. J., 2012, 18, 4953-4964.

38 J. L. Liu, Y. Liu, Q. Liu, C. Y Li, L. N. Sun and F. Y. Li, Iridium(III) Complex-Coated Nanosystem for Ratiometric Upconversion Luminescence Bioimaging of Cyanide Anions, J. Am. Chem. Soc., 2011, 133, 15276-15279.

39 L. Cheng, K. Yang, M. W. Shao, S. T. Lee and Z. Liu, Multicolor in vivo imaging of upconversion nanoparticles with emissions tuned by luminescence resonance energy transfer, J. Phys. Chem. C, 2011, 115, 2686-2692.

40 Z. Q. Li, Y. Zhang and S. Jiang, Multicolor core/shellstructured upconversion fluorescent nanoparticles, Adv. Mater., 2008, 20, 4765-4769.

41 J. S. Hu, X. F. Wu, Y. X. Liu, et al. Modulating upconversion luminescence through fluorescent dyes, J. Solid State Chem., 2017, 255, 139-144. 